\title{
BMJ Open Development of an intervention to support patients and clinicians with advanced lung cancer when considering systemic anticancer therapy: protocol for the PACT study
}

\author{
Despina Anagnostou, ${ }^{1}$ Stephanie Sivell, ${ }^{1}$ Simon Noble, ${ }^{1}$ Jason Lester, ${ }^{2}$ \\ Anthony Byrne ${ }^{3}$ Catherine Sampson, ${ }^{1}$ Mirella Longo, ${ }^{1}$ Annmarie Nelson ${ }^{1}$
}

To cite: Anagnostou D, Sivell S, Noble S, et al. Development of an intervention to support patients and clinicians with advanced lung cancer when considering systemic anticancer therapy: protocol for the PACT study. BMJ Open 2017;7:e015277. doi:10.1136/ bmjopen-2016-015277

- Prepublication history and additional material for this paper are available online. To view these files please visit the journal online (http://dx.doi. org/10.1136/bmjopen-2016015277).

Received 22 November 2016 Revised 10 May 2017 Accepted 26 May 2017

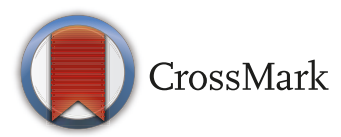

${ }^{1}$ Marie Curie Research Centre, School of Medicine, Cardiff University, Cardiff, UK

${ }^{2}$ Department of Clinical Oncology, Velindre NHS Trust UK, Cardiff, UK

${ }^{3}$ Department of Palliative Medicine, Cardiff and Vale University Health Board, Cardiff, UK

Correspondence to Dr Despina Anagnostou; anagnostoud@cardiff.ac.uk

\section{ABSTRACT}

Introduction Patient-centred care is essential to the delivery of healthcare; however, this necessitates direct patient involvement in clinical decision-making and can be challenging for patients diagnosed with advanced non-small cell lung cancer where there may be misunderstanding of the extent of disease, prognosis and aims of treatment. In this context, decisions are complex and there is a need to balance the risks and benefits, including treatment with palliative intent. The aim of the PACT study is to identify the information and decision support needs of patients, leading to the development of an intervention to support patients with advanced lung cancer when considering treatment options.

Methods and analysis PACT is a five-stage, multimethod and multicentre study. Participants: Patients and health professionals will be recruited from three health boards. Methods: Non-participant observation of multidisciplinary team meetings $(n=12)$ will be used to determine patients' allocation to treatment pathways (stage I). Non-participant observation of patient-clinician consultations ( $n=20-30$ ) will be used to explore communication of treatment options and decisionmaking. Extent of participation in decision-making will be assessed using the Observing Patient Involvement in Shared Decision-Making tool. Interviews with patients (stage III) and their clinicians (stage IV) will explore the perception of treatment options and involvement in decision-making. Based on stages I-IV, an expert consensus meeting will finalise the content and format of the intervention. Cognitive interviews with patients will then determine the face validity of the intervention (stage V). Analysis: analysis will be according to data type and research question and will include mediated discourse analysis, thematic analysis, framework analysis and interpretative phenomenological analysis.

Ethics and dissemination Ethical approval has been granted. The study findings will contribute to and promote shared and informed decision-making in the best interest of patients and prudent healthcare. We therefore aim to disseminate results via relevant respiratory, oncology and palliative care journals and conferences.
Strengths and limitations of this study

- A multimethod qualitative approach, tailored to each phase, research question and data type, is used to inform the development of a complex intervention.

- The findings from this study will provide an in-depth analysis of key turning points influencing information sharing, communication and decision-making between patients and clinicians when considering treatment options following a diagnosis of advanced lung cancer over time.

- Multidisciplinary teams located in Wales are used and their meeting proceedings might not entirely represent the rest of the UK.

\section{INTRODUCTION}

With an estimated 1.6 million of people dying every year, lung cancer remains a worldwide health problem ${ }^{1}$ and is the second most common cancer in the UK. In 2014, over 40000 new cases were diagnosed. ${ }^{2}$ Histologically, $80 \%$ of lung cancer relate to non-small cell type, ${ }^{2}$ which is incurable by cancer treatments at later stages.

Unfortunately, lung cancer is often diagnosed when the cancer is in its advanced stage; in 2008, it was estimated that three-quarters of the newly diagnosed patients in England and Wales were diagnosed with a stage III or IV cancer. ${ }^{2}$ For non-small cell lung cancer (NSCLC), the 1-year and 10-year survival rates for stage III disease are $35 \%$ and $6 \%$, respectively, while for patients presenting with stage IV disease, the 1-year survival rate is $14 \%$, with a median survival of 6-8 months. ${ }^{2}$

Although various targeted therapies have helped to increase survival rates for small subgroups of patients, combination chemotherapies remain the dominant approach towards treatment for NSCLC. ${ }^{34}$ For these 
patients, who cannot be offered curative treatments, the National Institute for Health and Clinical Excellence ${ }^{5}$ guidelines highlight the potential benefit of palliative care and recommend that patients who may benefit from palliative care services should be referred without delay.

\section{Patient involvement in decision-making}

From a societal perspective, lung cancer also raises issues of inequalities. Lung cancer is strongly associated with smoking, which, similarly to other poor health-related lifestyle behaviours, is linked to socioeconomic status. ${ }^{6}$ In the UK, survival rates are poorer among patients from lower socioeconomic and minority ethnic groups and cancer severity at diagnosis increases with age. ${ }^{7}$ Age and socioeconomic status can in turn affect patients' competency to actively engage in the consultation should they wish so. This means that any intervention aiming at improving patient participation in the consultations around treatment pathways will also lead to fairer access to healthcare. ${ }^{8}$

Shared decision-making (SDM) has been identified as the pinnacle of patient-centred care ${ }^{910}$ because it legitimises the patient's right to make decisions about their care. ${ }^{11}$ Crucial to this process is a commitment from both parties to exchange information. ${ }^{12}{ }^{13}$ Clinicians provide reliable evidence-based information on the likely benefits and harms of interventions or actions, including any uncertainties and risks while patients convey information about the effect of the illness on their lives, their values and their preferences. Patient's knowledge, preferences and priorities are taken into account alongside the clinician's expertise.

The UK Government aims to place patients' needs, wishes and preferences at the heart of the clinical decision-making by making SDM the norm throughout the National Health Service (NHS) ${ }^{14}$ However, SDM is far from being routinely implemented alongside the patient clinical care pathway. ${ }^{11}$ Joseph-Williams and colleagues ${ }^{15}$ reviewed patient-reported barriers and facilitators to SDM and identified two main themes: 'how the healthcare system is organised' (time, continuity of care, workflow and characteristics of the healthcare setting) and "what happens during the decision-making interaction' (patient characteristics, power imbalance in the patient-clinician relationship, preparation for an SDM encounter and preparation for an SDM process). The authors conclude that patients need knowledge and feel empowered to participate in SDM and that any interventions aiming to improve SDM should take account of the relationships between these factors and focus on both sides.

Patients diagnosed with advanced NSCLC are having to live with a poor prognosis. Treatment decisions made within the context of end of life care are undoubtedly complex; however, it cannot be assumed that restricted options should be presented, and these patients are too sick to be involved in SDM. Belanger and colleagues concluded that although a substantial minority prefers passive roles, the majority of terminally ill patients want

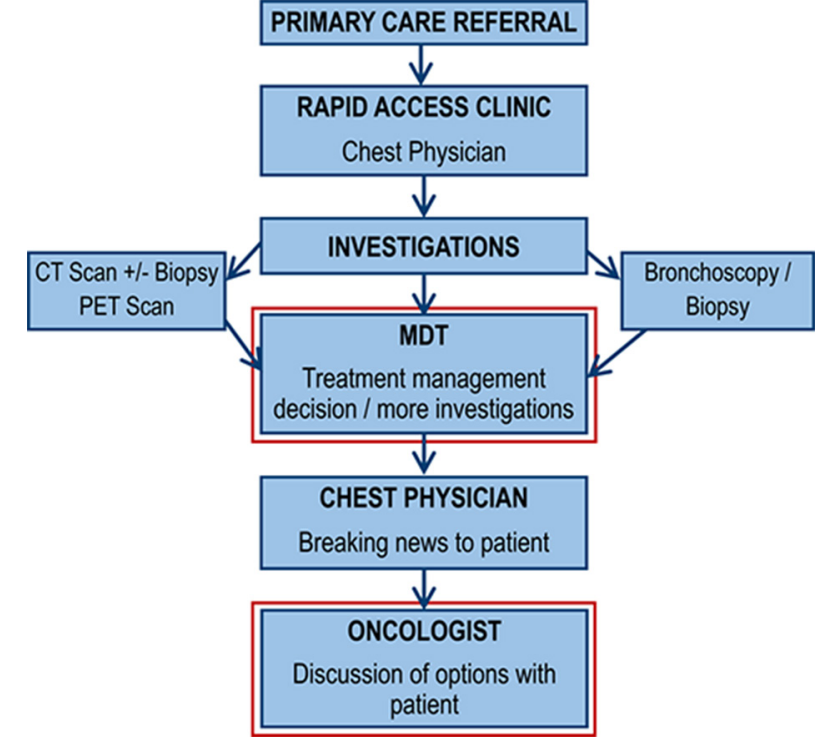

Figure 1 The lung cancer patient pathway. MDT, multidisciplinary team; PET, positron emission tomography.

to participate in their treatment decisions. ${ }^{16}$ Unmet information needs, unrealistic expectations, the way options are framed and delaying decisions constitute barriers to SDM. These factors echo and complement findings by Joseph-Williams and colleagues. ${ }^{15}$ Patients with advanced, life-limiting cancer express a desire for full information, with two-thirds of patients wanting to actively participate in decision-making. ${ }^{17}$

For patients with lung cancer, Lifford ${ }^{18}$ found that SDM was not routinely implemented, patients' individual values were not elicited and treatment decisions were not deliberated together. ${ }^{18}$ Patients experience significant misunderstandings concerning the extent of disease, prognosis and the aims of treatment, and there is evidence of an ongoing process of collusion concerning 'false optimism' communicated and shared by patients and their physicians. ${ }^{19}$ Given the prior mediation of treatment management within multidisciplinary team (MDT) meetings, which take place after initial diagnosis (figure 1), it is possible that patients are further disenfranchised from the decision-making process during the patient-clinician consultation stage, as they may not receive full disclosure of all available treatment options, including associated benefits and burdens, to help aid and inform their decision-making. ${ }^{17} 20$ Even when physicians discuss options between different treatments, they find difficult to discuss the option of no 'treatment' despite the advance stages of cancer disease. $^{21}$

The limitations of available treatments for lung cancer, balanced against the increasing and compelling evidence for a combined approach of oncology and palliative care, indicate the need to enable clinicians to introduce palliative care as an option at an early stage. ${ }^{522}$ However, timely referral to palliative care services might be complicated by patient's poor understanding of palliative care services and intentions ${ }^{23}$ and clinicians' concern about removing hope $^{24}$ although evidence in fact suggests that the 
opposite is the case, with patients feeling more involved in decision-making when given the opportunity to speak about palliative care..$^{25} 26$

The ability to discuss palliative care while managing its associated connotations is challenging; however, early palliative interventions can lead to less aggressive treatment, limit futile treatments and reduce symptom severity and problems associated with medical interactions while improving patients' quality of life, overall mood and satisfaction with care. ${ }^{27-29}$ In addition to this, there is now a growing body of evidence to suggest that systemic anticancer therapy (SACT) for certain patients and cancer characteristics is likely to increase early treatment-related mortality. ${ }^{30-34}$ Four of these studies were UK based and one included 9634 patients diagnosed with NSCLC. ${ }^{34}$

Patients want more information than their clinicians perceive they do, ${ }^{35}$ and physicians poorly predict these preferences within the context of palliative care. ${ }^{35}{ }^{36}$ For all the above reasons, a clear understanding of the balance of risk and benefits of SACT treatment and other options, such as palliative care, and of patients' preferences are critical to promote shared and informed decision-making in the best interest of patients and prudent healthcare. ${ }^{37}$

\section{Aims and objectives}

The PACT study aims to identify the information and decision support needs of patients diagnosed with advanced NSCLC and aims to develop an intervention to support those patients and their clinicians when considering treatment options, including SACT and/or referral to, or integration with, palliative care. The objectives are to:

1. Study how treatment decisions are determined for patients with lung cancer and how patients are allocated to treatment pathways during MDT interactions.

2. Explore communication of treatment options and capture patients' involvement in decision-making during doctor-patient consultations.

3. Explore patients' and clinicians' understanding and attitudes towards the delivery of treatment options for lung cancer and risk/benefits.

4. Capture patients' and clinicians' experiences of their consultation meetings and discussions in relation to perceptions of the available treatment options and of their involvement in decision-making.

5. Develop and face-test an intervention to support patients and clinicians when considering treatment options.

\section{METHODS}

\section{Study design}

PACT is a prospective, multimethod and multicentre study. The data collection process is sequential and has been designed to generate a rich understanding of the treatment decision-making process for NSCLC, starting from the beginning point of the MDT meeting and ending with the oncology appointment with the patient,

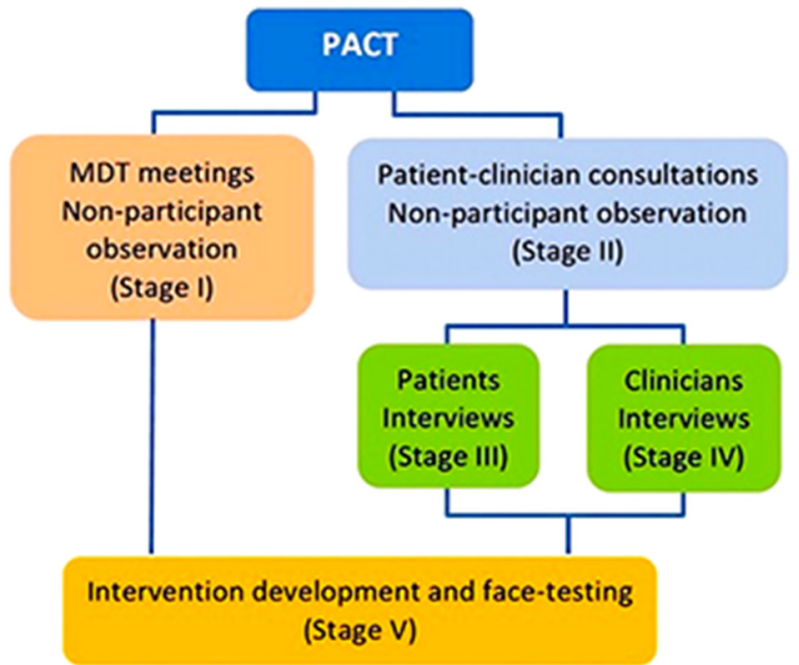

Figure 2 PACT study design. MDT, multidisciplinary team.

following the patient pathway within the UK healthcare system (figure 1).

The methodology comprises five stages (figure 2).

Stage I is a discrete event and will not influence participant selection in the later stages of the project. The data collected in stages 2-4 will be related to the same patient/ doctor dyad. If a companion is present, they will be also invited and recruited to the study.

\section{Recruitment and sampling}

Recruitment and data collection will take place in three NHS respiratory oncology clinics, set within three different health boards in Wales (see online supplementary 1). Participants' enrolment started in 2015 and is expected to end in 2017.

\section{Observation of lung MDT meeting (stage I)}

The aim is to study how treatment decisions are determined and how patients are allocated to treatment pathways. Four lung MDT meetings will be observed for each health board. Consent for data collection will be negotiated via nominated chairpersons of the meeting. Information sheets and consent forms signed by all contributing members are required for an MDT meeting to be considered for data collection.

Direct non-participant observation will be employed. ${ }^{38}$ Non-participant observation enables the recording of non-verbal communication, interactional behaviours and proxemics. ${ }^{39} 40$ Audio recording will minimise bias, securing the actual verbatim of participants' interactions. ${ }^{3841}$ One or more researchers will observe the MDT. Researchers will be selected for their methodological experience, academic background and familiarity with the clinical environment. They will be seated away from observed communications and will keep initial field notes and manage the digital recorder. Field notes will specify date, time, location and study site (see online supplementary 2). Observations regarding meeting membership, seating arrangements, equipment used and time keeping 
will be made. Patient-specific observations will also be made, focusing on the presentation of the patient, any information provided and considered, the key contributors to discussion, the process of decision-making and the nature of negotiation or how this is managed. In-depth, descriptive and reflective notes recording the researcher's observations will be completed as soon as possible after each observed consultation. ${ }^{414}$

Thematic analysis and mediated discourse analysis will be used to analyse the MDT data. Thematic analysis ${ }^{43}$ will identify the most appropriate segments of data for further exploration with mediated discourse analysis. Thematic analysis will follow Brawn and Clarke's model and use five phases to establish meaningful patterns and issues of potential interest: (a) familiarisation with the data, (b) generating initial codes, (c) searching for themes among codes, (d) reviewing themes and (e) defining and naming themes. ${ }^{44}$

The MDT meetings are events with established memberships, customs and practices, which may differ across health boards. Mediated discourse analysis, a focus on discourse in action in communities of practice, will be used to explore the interactions and discussions between MDT attendees, examining how treatment decisions are determined, as well as the communication patterns and decision-making processes of the MDT members. ${ }^{45}$ The focus of mediated discourse analysis is the whole intersection of group social practices, team dynamics, spatial dynamics and the cultural traditions of the team, of which discourse is a part. Hence, attention will be paid to the power dynamics of the meeting with a deeper analysis of critical or key moments of interactions which involve decisions, use of questions that explore risks and benefits of alternative options by different members of the team, agreement and disagreement in diagnosis and treatment recommendations.

\section{Observation of patient-clinician consultation (stage II)}

Stage II aims to explore the communication of treatment options and to capture patient's involvement in decision-making. It also aims to understand their perceptions of the discussion around treatment options.

Clinicians who work with patients to discuss treatment options at each of the three sites are eligible to participate. The researcher will discuss the project with them and provide information sheets and consent forms. Clinicians who agree to participate will sign individual consent forms before approaching patients about PACT.

Patients and their companions (ie, persons accompanying patients to consultation meetings) will be offered recruitment to the study in order that their communications may also be captured. Clinicians will identify eligible patients after their MDT allocation to oncology. Between 7 and 10 participants (and their respective clinicians) will be recruited from each health boards. Inclusion and exclusion criteria are listed in table 1.

The clinical team at each site will identify and introduce the study to eligible patients. These prospective
Table 1 Participants' inclusion and exclusion criteria

\begin{tabular}{ll}
\hline Inclusion criteria & Exclusion criteria \\
\hline Over the age of 18 years & $\begin{array}{l}\text { Recommendation by the } \\
\text { MDT for radical treatment } \\
\text { of underlying lung cancer } \\
\text { or best supportive care } \\
\text { without SACT }\end{array}$ \\
$\begin{array}{l}\text { In receipt of an advanced NSCLC } \\
\text { diagnosis }\end{array}$ & $\begin{array}{l}\text { Any factor that prohibits } \\
\text { communication or } \\
\text { comprehension, } \\
\text { including an inability to } \\
\text { communicate in English }\end{array}$ \\
$\begin{array}{l}\text { Be the subject of discussions } \\
\text { at an MDT where a decision/ } \\
\text { recommendation was made } \\
\text { for SACT (including first-line or } \\
\text { second-line chemotherapy) }\end{array}$ \\
\hline Able and willing to give informed
\end{tabular}

Able and willing to give informed

consent

\section{Communicate sufficiently to}

partake in an interview

MDT, multidisciplinary team; NSCLC, non-small cell lung cancer; SACT, systemic anti-cancer therapy.

participants will be given an information sheet and a letter with a reply slip. When the reply slip is returned, the researcher(s) will contact the participant to discuss the study and, if willing, to arrange to meet prior to their consultation. Consent will be taken by the observing researcher at their next clinic appointment. Where family members or companions are present, consent will be also sought. The contribution of family members/carers may represent a core component of the consultation and it is therefore important to capture. If the patient does not wish to take part, then the consultation will not be recorded and the patient/family will not be recruited to the study. If a companion does not consent to the study (in contrast to the patient wish), then their verbatim will be removed from the transcriptions and it will not be included in the analysis. In the case that more than one consultation is needed for a decision to be made, the researchers will follow the patient at their next appointment(s), and they will record the subsequent consultations.

Patient-clinician consultations will be audio-recorded on digital recorders. The researcher will manage the digital recorder and write field notes during the consultation. Observations will focus on proxemics, non-verbal communication and interactional behaviours. If participants do not wish to consent to the researcher being present, they will be given the option of our audio-recorded consultations.

Patient-clinician consultations will be measured using the Observing Patient Involvement in Shared Decision-Making (OPTION) instrument ${ }^{46}$ V.3. OPTION is a validated process outcome measure used to study the extent to which clinicians involve patient in decision-making within clinical consultations. The instrument 
has been used with a range of consultations. ${ }^{47}$ From the transcripts, the researcher will rate the clinician's level of expertise for 12 'patient-involving' behaviours on Likerttype scales ranging from 0 (no attempt to perform the behaviour) to 4 (the behaviour is performed to a high standard); the sum of these scores are standardised to provide a score of $0-100$ to indicate the 'overall level of patient-involving competencies' of the clinician during the consultation. Individual item scores will also be used to identify areas where additional information and/or a different approach to the presentation of the information may be of benefit. To validate results, a second researcher will independently score the consultations.

Thematic analysis ${ }^{43}$ will be used to explore in greater detail how treatment management options are presented to patients and their involvement in decision-making during their consultation with clinicians. Clinical members of the research team will assess any clinically orientated topics collected under the OPTION headings.

\section{Semi-structured interviews with patients (stage III)}

Stage III aims at capturing patients' experiences of their consultation in relation to perceptions of the available treatment options and their involvement in decision-making.

Patients and their companions who participated in stage II will be invited to face-to-face interviews. Information regarding interviews will be provided after observations. Signed consent from patients and companions (where present) will be taken by the researcher prior to the interview, subject to the participant having at least 24 hours to review the information sheets. Participants will be telephoned by the researcher within a week after their consultation to arrange a convenient date and time for the interview. Interviews will take place within 2 weeks of the observed consultation wherever possible and no later than 4 weeks. We would like to keep flexibility with the timeframe of 2-4 weeks, as some patients might start chemotherapy immediately after their consultation and, therefore, might not feel well enough to be interviewed that proximately. Similarly, if patients become too ill to participate after consultation, they will be withdrawn from the next stage of the study.

Semi-structured interviewing will be the primary data collection method for this stage. ${ }^{48}$ This will provide space for patients to share and reflect on thoughts and feelings regarding consultation experiences while allowing researchers to specifically explore questions regarding patients' understanding of treatment options and their involvement in treatment decision-making (see online supplementary 3). Questions are designed to mirror the OPTION instrument (see table 2), which will subsequently be used to inform data analysis.

The interviews will be conducted at a place of convenience for the patients (eg, their home, at the clinic). If a physical location proves inconvenient, interviews will be conducted by telephone, using call-recording equipment. Interviews are expected to be approximately $30-60 \mathrm{~min}$
Table 2 OPTION tool items

1. The clinician draws attention to an Identifying the identified problem as one that requires a problem decision-making process

2. The clinician states that there is more Explaining than one way to deal with the identified equipoise problem ('equipoise')

\section{The clinician assesses patient's} preferred approach to receiving

Assessing information to assist decision-making (eg, discussion in consultations, read printed material, assess graphical data, use videotapes or other media)

4. The clinician lists 'options' which can Listing options include the choice of 'no action'

5. The clinician explains the pros and cons of options to the patient (taking 'no and cons action' is an option)

$\begin{array}{ll}\begin{array}{l}\text { 6. The clinician explores the patient's } \\ \text { expectations (or ideas) about how the } \\ \text { problem(s) are to be managed }\end{array} & \begin{array}{l}\text { Exploring } \\ \text { expectations }\end{array} \\ \begin{array}{ll}\text { 7. The clinician explores the patient's } \\ \text { concerns (fears) about how the } \\ \text { problem(s) are to be managed }\end{array} & \begin{array}{l}\text { Explaining } \\ \text { concerns }\end{array} \\ \begin{array}{ll}\text { 8. The clinician checks the patient has } \\ \text { understood the information }\end{array} & \begin{array}{l}\text { Checking } \\ \text { understanding }\end{array} \\ \begin{array}{l}\text { 9. The clinician offers the patient explicit } \\ \text { opportunities to ask questions during the opportunities for } \\ \text { decision-making process }\end{array} & \begin{array}{l}\text { questions } \\ \text { Eliciting preferred }\end{array} \\ \begin{array}{l}\text { 10. The clinician elicits the patient's } \\ \text { preferred level of involvement in }\end{array} & \begin{array}{l}\text { involvement } \\ \text { decision-making }\end{array}\end{array}$

11. The clinician indicates the need for a decision-making (or deferring) Indicating need for stage (how the decision is made is not evaluated (could be paternalistic). How the decision is made between participants and who takes 'control' is not evaluated)

12. The clinician indicates the need to review the decision (or deferment)

Indicating need to review/defer

OPTION, Observing Patient Involvement in Shared DecisionMaking.

in length, and these may be terminated at any point if a patient participant indicates they wish to stop, if they are clearly fatigued or if they become unwell.

Interviews will be recorded and transcribed verbatim. Field notes made with participant's permission will record details of specific incidents occurring during the interview and any non-verbal communication. If any participants wish to be interviewed over the phone, attention to decreased engagement and verbal probing to check on participants' fatigue will be initiated by the researcher, whereas non-verbal communication will be missed. 
The right of the participant to refuse to participate in the study without giving reasons will be respected. Similarly, the participant will remain free to withdraw at any time from the study. All data will be withdrawn at request.

In the event of participant distress due to discussion of sensitive topics, or if a clinical or work-related issue emerges, the researchers, using their experience, will react at the time and will refer the issue to the participant's clinical team, with their permission.

A framework analysis ${ }^{49} 50$ approach will be used to explore the pre-determined areas of interest informed by the OPTION instrument. Interpretative phenomenological analysis (IPA) will be also used to explore key emergent themes from the semi-structured interviews, focusing on how patients interpret their experience of the consultation process. ${ }^{51}$ IPA aims to understand the meaning that events or states have for participants based on their subjective accounts. The transcript of each interview will be analysed sequentially, following four stages: (a) preliminary reading, (b) initial comments are grouped into themes, (c) connections between themes is developed until an organised master list and thematic account of the case is achieved and (d) subsequent transcripts: new themes will be tested against the previous cases as non-recurring themes are tested against following cases. Connections across cases will be noted to identify a set of super-ordinate themes for the group. ${ }^{51}$

\section{Semi-structured interviews with clinicians (stage IV)}

Stage IV aims to explore clinicians' views on treatment management options for patients with lung cancer, their experiences in presenting these options to patients (with a focus on risk/benefit) and their perceptions on how involved patients are in their treatment decisions. Similarly to phase III, face-to-face semi-structured interviews will be used and questions will follow the OPTION instrument domains.

Clinicians participating in the observations of patientclinician consultations will be interviewed across the three different health boards. Clinicians will be consented to the interview at the same time as they consent to the observation of their patient consultations. Signed consent from the clinicians will be taken by the researcher at the time of interview subject to the participant having at least 24 hours to review the information sheets.

The right of the clinician to refuse to participate in the study without giving reasons will be respected. Similarly, the clinician will remain free to withdraw at any time from the study and all data will be withdrawn at request.

Interviews will take place as soon as possible following the observations of clinician's respective consultations. Clinicians will be interviewed at the clinician's clinic or office according to preference. If a face-to-face interview is not feasible, a telephone interview may be offered instead. Interviews will be approximately $30-60 \mathrm{~min}$ in length.

In the event of clinician distress due to discussion of sensitive topics, or if a clinical or work-related issue emerges, the researchers, using their experience, will react at the time and, if needed, they will advise clinicians to contact the BMA Counselling Service ${ }^{52}$ or they will refer the issue to the National Counselling Service for Sick Doctors, with the participants' permission. ${ }^{53}$

The interviews will be carried out by an experienced researcher under the remote supervision of a member of the research team. The researcher will digitally record the interview but may also make field notes (with the participant's permission) to record incidents occurring during the interview, non-verbal communication or reactions at the time of the interview.

As with the patient interviews, IPA will be used to explore how clinicians make sense of their situations in their personal context according to individual experience, values and training. ${ }^{51}$

\section{Intervention development (stage V)}

Phases I-IV will form an appropriate theoretical framework to guide the design, development and subsequent evaluation of the intervention. ${ }^{54}$ Stage $\mathrm{V}$ aims to develop an intervention and face-test it for its usability with a representative patient group. An expert panel of stakeholders will be convened and consulted to identify key components of the intervention and refine the design, development and content of the intervention in a consensus meeting. Methodologists with expertise in SDM and complex interventions, patients, carers, clinicians (lung cancer nurse specialists, oncologists, chest physicians and general practitioners) and lay representatives will be invited as stakeholders. Experts will be identified via a review of the most relevant literature in the field as well as clinical networks. Lay and professional stakeholders will be identified using patient and public involvement (PPI) networks. Information sheets and consent forms will be distributed via e-mail. Signed consent will be taken before the meeting.

The stakeholders meeting will follow the nominal group technique approach. ${ }^{55}$ This structured group discussion ensures contribution from each participant while minimising researcher bias. The expert consultation will help ensure that the appropriate evidence base is incorporated into the design of the intervention.

Group discussions will be recorded and transcribed verbatim. Field notes made with participant's permission will be made by the researcher(s). Thematic analysis ${ }^{43}$ and ranking exercises will be used to summarise the data.

The consensus meeting will lead to a national Delphi survey of the same stakeholders to prioritise items in relation to outcome measure, format and content of the proposed intervention.

The proposed intervention will be then face-tested for usability with a convenience sample of patients $(n=10-$ 15). Each participant will also be asked to take part in follow-up cognitive interviews. ${ }^{56}$ Potential participants will be recruited via participating MDTs and given information about the study. The inclusion and exclusion criteria applied within stage II will apply. Participants will be telephoned by a researcher and a convenient time and 
place for interview will be arranged. Signed consent from participants will be taken at the time of interview by the researcher, allowing at least 24 hours to review the information sheets.

Cognitive interviews are conducted face to face. Participants will be asked to answer questions outlined within the intervention tool, with the aim of collecting information about the content, format and ease of understanding regarding the proposed intervention. ${ }^{57}$ Both 'think aloud' and 'probe' cognitive interviews techniques will be applied. ${ }^{56}$

Scripted and spontaneous probing will be used, following Willis ${ }^{56}$ taxonomy of six categories: comprehension, paraphrasing, confidence judgement, recall, specific probes and general probes. The 'scripted' approach ensures that important aspects of the intervention are addressed. Complementing this approach, 'spontaneous' probing allows for an element of flexibility, enabling the interviewer to encourage further exploration on items which appear to be problematic. ${ }^{56} 58$ The interviewer will maintain an awareness of behavioural cues related to specific items or questions, noting any signs of discomfort or distraction for example.

Interviews will be recorded and transcribed verbatim and thematic analysis ${ }^{43}$ will be used to analyse the transcripts. The intervention tool will be adjusted, if necessary, following analysis of this dataset.

Phase $\mathrm{V}$ will finalise the format and content of the intervention to be subsequently tested via a multisite randomised controlled trial.

We anticipate the intervention to be a patient-facing intervention which will include information items alongside the care pathway for patients with NSCLC and items related to communication around treatment decisions (eg, benefits/risks, side effects). We anticipate that a key outcome of this intervention is to enhance patient-centred communication with regard to treatment decisions.

\section{ETHICAL CONSIDERATIONS}

The study follows the Research Governance Frameworks for England and Wales ${ }^{59} 60$ and guidelines from the National Patient Safety Agency. ${ }^{61}$ Ethical approval was granted in September 2015 (REC 14/WA/1103).

All participants will be able to withdraw at any point without impacting their medical care or relationship with their clinical team. Informed consent will be taken by the researcher collecting the data, who has undertaken Good Clinical Practice (research) training.

The PACT research team will preserve the confidentiality and anonymity of participants and handle all research data according to the principles of the Data Protection Act. ${ }^{62}$ Transcribed recordings will be anonymised before analysis. Data will be stored on a password-protected computer located in secure university buildings and appropriately backed up. Data transfer across participant organisations will be closely monitored and contractually agreed. All data will be retained for up to 15 years post study closure. Study documents will be retained for 15 years and then archived according to the MCPCRC policy.

\section{PPI AND STEERING GROUP}

PACT has established a steering group including clinicians and volunteer representatives, to monitor and guide collection and interpretation of the data. ${ }^{63}$ In line with guidance from Involving People ${ }^{64}$ and Involve, ${ }^{65}$ the PACT research team has recruited two lay, actively involved representatives. The lay representatives will contribute with ideas around recruitment of participants and ways to describe the study. The lay representatives will also contribute to interpret and contextualise the study findings. They will review selected transcripts and their comments will inform the data analysis and interpretation of findings. Additionally, the lay representatives will guide and contribute to the dissemination of the results to appropriate patient groups.

\section{DISSEMINATION}

We hope that study findings will provide evidence for the development of national guidelines for care, which support both the regional Wales Government initiative of 'achieving prudent healthcare ${ }^{37}$ and the international initiative of 'choosing wisely', currently led by the Medical Royal College in the UK, ${ }^{66}$ and reduce 'overtreatment'. Specific dissemination strategies of the study findings will include: (a) meetings with the clinicians involved into the study to ascertain how the study findings can enhance the MDT chart guidelines on best practice; (b) a lay summary of the study findings will be produced and disseminated among key patient support groups; (c) seminars will be given at departmental level; (d) local, national and international conference presentations will be made to disseminate both study methodology and findings; (e) peer-reviewed publications will include papers on the main study results and papers attached to specific study stage and methodology; (f) study newsletters will be regularly produced and disseminated to key stakeholders; and (g) media and press releases via the Marie Curie Palliative Care Research Centre and Twitter and Facebook accounts.

Correction notice This article has been corrected since it was published Online First. In the Contributor statement, the initials SC have been corrected to SS as it refers to name Stephanie Sivell.

Acknowledgements The authors would like to thank the patients' representative Mrs Lesley Radley and Mr Dave Jones for commenting on the draft of this manuscript.

Contributors AN conceived and designed the study. AN, SN, AB, SS, JL and DA developed the study protocol. DA drafted the manuscript, and AN, ML, CS and SS contributed to the drafting of the manuscript. All authors reviewed and commented on the drafts of this manuscript. DA managed ethics and coordinates the study fieldwork, including sampling and data collection, supported by CS. All authors are expected to make substantial contributions to the analysis and interpretation of the data. All authors read and approved the final manuscript.

Funding This study is supported by The Velindre Stepping Stones Appeal within Velindre NHS Trust Charitable Funds; grant number 2013/009. 
Competing interests $\mathrm{JL}$ and SN have been fundraisers for the Stepping Stones Charity (the funder) and hold places on the Steering Committee. However, they have no direct decision making powers regarding awarding funds which is managed by Velindre Cancer Centre Charitable Funds Committee. This does not constitute conflict of interest.

Patient consent Obtained.

Ethics approval Wales REC 6.

Provenance and peer review Not commissioned; externally peer reviewed.

Open Access This is an Open Access article distributed in accordance with the Creative Commons Attribution Non Commercial (CC BY-NC 4.0) license, which permits others to distribute, remix, adapt, build upon this work non-commercially, and license their derivative works on different terms, provided the original work is properly cited and the use is non-commercial. See: http://creativecommons.org/ licenses/by-nc/4.0/

(c) Article author(s) (or their employer(s) unless otherwise stated in the text of the article) 2017. All rights reserved. No commercial use is permitted unless otherwise expressly granted.

\section{REFERENCES}

1. Ferlay J, Soerjomataram I, Dikshit R, et al. Cancer incidence and mortality worldwide: sources, methods and major patterns in GLOBOCAN 2012. Int J Cancer 2015;136:E359-E386.

2. Cancer Research UK. Lung Cancer Statistics. Secondary Lung Cancer Statistics. 2014. http://www.cancerresearchuk.org/healthprofessional/cancer-statistics/statistics-by-cancer-type/lung-cancer/ incidence\#heading-Three.

3. National Cancer Institute. Non-small cell lung cancer treatment Stage IV NSCLC treatment. USA: National Institute of Health, 2014

4. Garon EB, Rizvi NA, Hui R, et al. Pembrolizumab for the treatment of non-small-cell lung cancer. N Engl J Med 2015;372:2018-28.

5. National Institute for Health and Clinical Excellence. Lung cancer: the diagnosis and treatment of lung cancer. 2011. CG121.

6. Denney JT, Krueger PM, Pampel FC, et al. Socioeconomic Status and Health Behaviors. The Wiley Blackwell Encyclopedia of Health, IIIness, Behavior, and Society. T. John Wiley \& Sons, Ltd, 2014:2223-7.

7. Aoun S, Kristjanson L, McConigley R, et al. Palliative care for people with motor neurone disease: how effective is an educational program for service providers? Palliative Medicine 2012;26:486-7.

8. Appleby J, Raleigh V, Frosini F, et al. Variations in health care: the good, the bad and the inexplicable. King's Fund, 2011.

9. Barry MJ, Edgman-Levitan S. Shared decision making--pinnacle of patient-centered care. N Engl J Med 2012;366:780-1.

10. Elwyn G, Frosch D, Thomson R, et al. Shared decision making: a model for clinical practice. J Gen Intern Med 2012;27:1361-7.

11. Coulter A, Collins A. Making shared decision-making a reality. London: King's Fund, 2011.

12. Charles C, Gafni A, Whelan T. Shared decision-making in the medical encounter: what does it mean? (or it takes at least two to tango). Soc Sci Med 1997;44:681-92.

13. Charles C, Gafni A, Whelan T. Decision-making in the physicianpatient encounter: revisiting the shared treatment decision-making model. Soc Sci Med 1999;49:651-61.

14. Coulter A, Edwards A, Elwyn G, et al. Implementing shared decision making in the UK. Z Evid Fortbild Qual Gesundhwes 2011;105:300-4

15. Joseph-Williams N, Elwyn G, Edwards A. Knowledge is not power for patients: a systematic review and thematic synthesis of patientreported barriers and facilitators to shared decision making. Patient Educ Couns 2014;94:291-309.

16. Bélanger E, Rodríguez C, Groleau D. Shared decision-making in palliative care: a systematic mixed studies review using narrative synthesis. Palliat Med 2011;25:242-61.

17. Jenkins V, Fallowfield L, Saul J. Information needs of patients with cancer: results from a large study in UK cancer centres. $\mathrm{Br} \mathrm{J}$ Cancer 2001;84:48-51.

18. Lifford $R$. Shared decision making about lung cancer treatments [DClinPsychol]. Leeds University 2012.

19. Gaston $\mathrm{CM}$, Mitchell $\mathrm{G}$. Information giving and decision-making in patients with advanced cancer: a systematic review. Soc Sci Med 2005;61:2252-64.

20. Archer VR, Billingham LJ, Cullen MH. Palliative chemotherapy: no longer a contradiction in terms. Oncologist 1999;4:470-7.

21. Brom L, De Snoo-Trimp JC, Onwuteaka-Philipsen BD, et al. Challenges in shared decision making in advanced cancer care: a qualitative longitudinal observational and interview study. Health Expect 2017;20:69-84.

22. Smith TJ, Temin S, Alesi ER, et al. American society of clinical oncology provisional clinical opinion: the integration of palliative care into standard oncology care. J Clin Oncol 2012;30:880-7.

23. Mcllfatrick S, Noble H, McCorry NK, et al. Exploring public awareness and perceptions of palliative care: a qualitative study. Palliat Med 2014;28:273-80.

24. Sleeman KE. End-of-life communication: let's talk about death. J $R$ Coll Physicians Edinb 2013;43:197-9.

25. Davison SN, Simpson C. Hope and advance care planning in patients with end stage renal disease: qualitative interview study. BMJ 2006;333:886.

26. Godlee F. Who are we treating? BMJ 2014;348.

27. Temel JS, Greer JA, Muzikansky A, et al. Early palliative care for patients with metastatic non-small-cell lung cancer. $N$ Engl J Med 2010;363:733-42.

28. Zimmermann C, Swami N, Krzyzanowska M, et al. Early palliative care for patients with advanced cancer: a cluster-randomised controlled trial. Lancet 2014;383:1721-30.

29. Harris I, Murray SA. Can palliative care reduce futile treatment? A systematic review. BMJ Support Palliat Care 2013;3:389-98.

30. Khoja L, McGurk A, O'Hara C, et al. Mortality within 30 days following systemic anti-cancer therapy, a review of all cases over a 4 year period in a tertiary cancer centre. Eur J Cancer 2015;51:233-40.

31. National Confidential Enquiry into Patient Outcome and Death (NCEPOD). For better, for worse? A review of the care of patients who died within 30 days of receiving systemic anti-Cancer therapy. London, UK: National Confidential Enquiry into Patient Outcome and Death, 2008.

32. O'Brien MR, Whitehead B, Murphy PN, et al. Social services homecare for people with motor neurone disease/amyotrophic lateral sclerosis: why are such services used or refused? Palliat Med 2012;26:123-31.

33. Yoong J, Seah JA, Hamilton K, et al. Mortality within 30 days of receiving systemic anti-cancer therapy at a regional oncology unit: what have we learned? Asia Pac J Clin Oncol 2012; 8:325-9.

34. Wallington M, Saxon EB, Bomb M, et al. 30-day Mortality after systemic anticancer treatment for breast and lung cancer in England: a population-based, observational study. Lancet Oncol 2016;17:1203-16.

35. Gattellari M, Voigt KJ, Butow PN, et al. When the treatment goal is not cure: are cancer patients equipped to make informed decisions? $J$ Clin Oncol 2002;20:503-13.

36. Vos MS, Putter $\mathrm{H}$, van Houwelingen $\mathrm{HC}$, et al. Denial and physical outcomes in lung cancer patients, a longitudinal study. Lung Cancer 2010;67:237-43.

37. Bradley $\mathrm{P}$, Wilson $\mathrm{A}$, Buss $\mathrm{P}$, et al; Achieving prudent healthcare in NHS Wales. Cardiff: Public Health Wales, 2014.

38. Caldwell K, Atwal A. Non-participant observation: using video tapes to collect data in nursing research. Nurse Res 2005;13:42-54.

39. Polit DF, Beck CT. Nursing research: principles and methods. Lippincott Williams \& Wilkins, 2004.

40. Mulhall A. In the field: notes on observation in qualitative research. $J$ Adv Nurs 2003;41:306-13.

41. Audrey S. Qualitative research in evidence-based medicine: improving decision-making and participation in randomized controlled trials of cancer treatments. Palliat Med 2011; 25:758-65.

42. Brewer J. Ethnography. Milton Keynes: Open University Press, 2000.

43. Attride-Stirling J. Thematic networks: an analytic tool for qualitative research. Qualitative Research 2001;1:385-405.

44. Braun V, Clarke V. Using thematic analysis in psychology. Qual Res Psychol 2006;3:77-101.

45. Scollon R. Mediated discourse: the nexus of practice. London/New York: Routledge, 2001.

46. Elwyn G, Hutchings H, Edwards A, et al. The OPTION scale: measuring the extent that clinicians involve patients in decisionmaking tasks. Health Expect 2005;8:34-42.

47. Couët N, Desroches S, Robitaille H, et al. Assessments of the extent to which health-care providers involve patients in decision making: a systematic review of studies using the OPTION instrument. Health Expect 2015;18:542-61.

48. Kelly SE, Bourgeault I, Dingwall R. Qualitative interviewing techniques and styles. The Sage handbook of qualitative methods in health research 2010:307-26.

49. Ritchie J, Spencer L. Qualitative data analysis for applied policy research. The qualitative researcher's companion 2002:305-29.

50. Pope C, Ziebland S, Mays N, et al. Analysing qualitative data. Bmj 2000;320:114-6. 
51. Smith J, Flower P, Larkin M. Interpretative phenomenological analysis: theory, method and research. London: Sage, 2009.

52. BMA. BMA Counselling Service. Secondary BMA Counselling Service. 2014. http://bma.org.uk/practical-support-at-work/doctorswell-being/websites-for-doctors-in-difficulty.

53. NCSSD. National Counselling Service for Sick Doctors Secondary National Counselling Service for Sick Doctors. 2014. http://www. ncssd.org.uk/.

54. Craig P, Dieppe P, Macintyre S, et al. Developing and evaluating complex interventions. Medical Research Council, UK 2011.

55. Potter M, Gordon S, Hamer P. The nominal group technique: a useful consensus methodology in physiotherapy research New Zealand. Journal of Physiotherapy 2004;32:126-30.

56. Willis GB. Cognitive interviewing: a tool for improving questionnaire design: Sage Thousand Oaks. CA 2005.

57. Daveson BA, Bechinger-English D, Bausewein C, et al. Constructing understandings of end-of-life care in Europe: a qualitative study involving cognitive interviewing with implications for cross-national surveys. J Palliat Med 2011;14:343-9.

58. Murtagh FE, Addington-Hall JM, Higginson IJ. The value of cognitive interviewing techniques in palliative care research. Palliat Med 2007;21:87-93.
59. Department of Health. Research governance framework for health and social care. 2009.

60. Welsh Assembly Government. Research Governance Framework for Health and Social Care in Wales. 2nd edn, 2009.

61. National Patient Safety Agency. Information Sheets and Consent Forms: Guidance for Researchers and Reviewers. 2011. www.nres. npsa.nhs.uk/EasysiteWeb/getresource. axd?AssetID=338\&type=full\& servicetype=Attachment.

62. UK Parliament. Data Protection Act. London: HMSO, 1998.

63. Tischler V, D'Silva K, Cheetham A, et al. Involving patients in research: the challenge of patient-centredness. Int J Soc Psychiatry 2010;56:623-33.

64. Moore B, Porteous C, Simon N. Pathways for Involving People in Social Care and Health Research in Wales: a Signposting Document. 2007. http://www.involvingpeople.org.uk/.

65. Fitzgibbon J, Hanley B, Muir D, et al. Public involvement in clinical trials: supplement to the briefing notes for researchers. 2012. http:// www.invo.org.uk/wp-content/uploads/2012/04/INVOLVEpublicinvolv ementinclinicaltrialsBriefingnotes2012.pdf.

66. Malhotra A, Maughan D, Ansell J, et al. Choosing Wisely in the UK: the Academy of Medical Royal Colleges' initiative to reduce the harms of too much medicine. BMJ 2015;350:h2308. 